\title{
Flying with Respiratory Disease
}

\author{
Panagiota Tzani $^{\mathrm{a}}$ Giovanna Pisi $^{\mathrm{b}}$ Marina Aiello $^{\mathrm{a}}$ Dario Olivieri $^{\mathrm{a}}$ \\ Alfredo Chetta ${ }^{a}$ \\ ${ }^{a}$ Clinica Pneumologica, Dipartimento Cardio-Polmonare and ${ }^{b}$ Centro Fibrosi Cistica, \\ Dipartimento Materno-Infantile, Azienda Ospedaliero-Universitaria di Parma, Parma, Italy
}

\section{Key Words}

Air travel, respiratory diseases - Fitness for flight assessment $\cdot$ Hypobaric hypoxia $\cdot$ Hypoxia altitude simulation test

\begin{abstract}
Patients with respiratory diseases may be at risk during flight because at cruising altitude an important hypobaric hypoxia may occur. The only absolute contraindications to flying in these patients are pneumothorax, bronchogenic cyst and severe pulmonary hypertension. In order to evaluate the risks related to air travel in patients with respiratory diseases, an evaluation of their fitness to fly, including the hypoxia altitude simulation test, is required. The fitness to fly evaluation can identify patients requiring supplemental oxygen during flight which is provided by most airlines when prescribed by the passenger's physician. This review deals with the cardiorespiratory effects of flight, the risks associated with respiratory diseases during air travel and the procedures to follow in order to assess fitness to fly in patients with respiratory disorders.

Copyright $\odot 2010$ S. Karger AG, Basel
\end{abstract}

\section{Introduction}

More than a billion people travel by air each year around the world $[1,2]$. Among them, the number of people affected by respiratory diseases is increasing [3]. Air travel may be risky in these patients because an important hypobaric hypoxia may occur at cruising level $[4,5]$. In fact, respiratory as well as gastrointestinal and cardiac disorders are among the most frequent disorders reported during air travel, after neurological problems [6]. The aim of this review is to deal with the cardiorespiratory effects of flight, the risks associated with respiratory diseases during air travel and the procedures to follow in order to assess fitness to fly in patients with respiratory disorders.

\section{Effects of Altitude on Cardiopulmonary Function}

The percentage of oxygen in the air is $21 \%$ at sea level and barometric pressure ranges around $760 \mathrm{~mm} \mathrm{Hg}$. In the troposphere, which is up to $18,000 \mathrm{~m}$ above sea level (osl), as altitude increases, the percent of oxygen does not vary, whereas barometric pressure decreases gradually until it is halved at approximately $6,000 \mathrm{~m}$ osl. As barometric pressure decreases, partial inspiratory oxygen pressure $\left(\mathrm{PiO}_{2}\right)$ decreases consequently as well. Changes

Dr. Panagiota Tzani

Clinica Pneumologica, Azienda Ospedaliero-Universitaria

Padiglione Rasori, Viale Rasori 10

IT-43126 Parma (Italy)

Tel. +39 0521703 429, Fax +390521 292 615, E-Mail panayotat@yahoo.com 


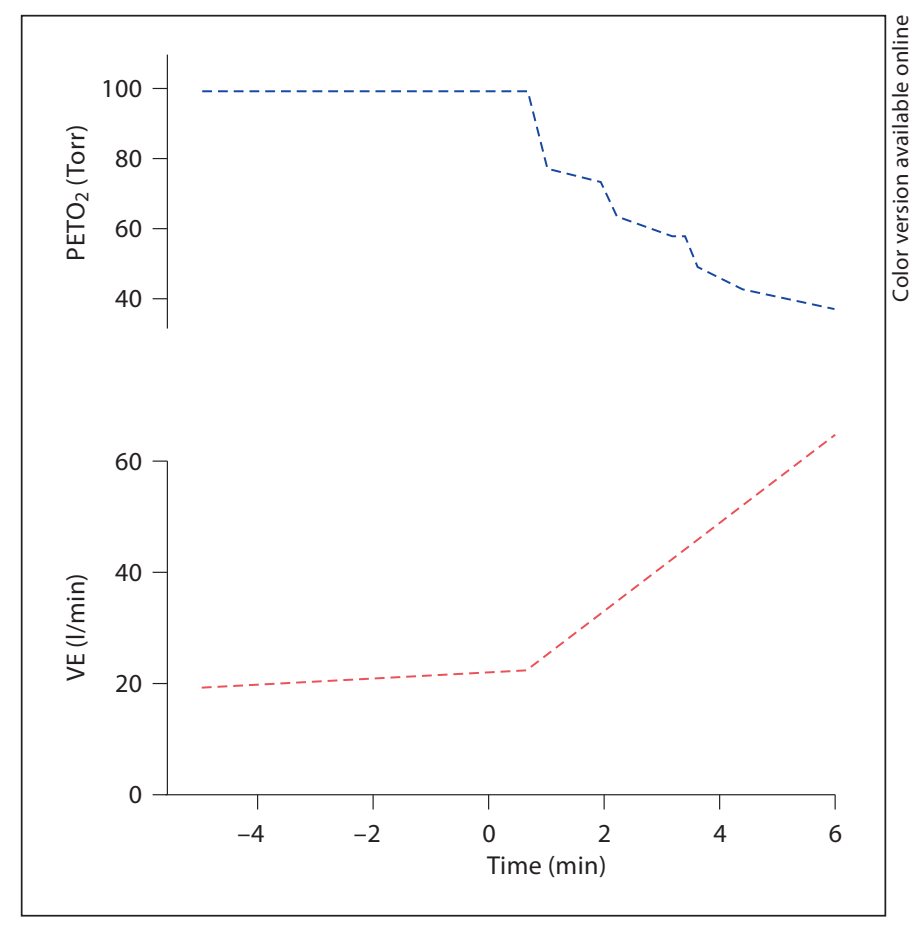

Fig. 1. Schematic representation of changes in minute ventilation with progressive hypoxia in healthy subjects. Modified from Zhang and Robbins [11]. PETO $_{2}=$ End-tidal partial oxygen pressure; $\mathrm{VE}=$ minute ventilation.

in $\mathrm{PiO}_{2}$ and in partial arterial oxygen pressure $\left(\mathrm{PaO}_{2}\right)$ in relation to altitude are listed in table 1 . Notably, ordinary flights reach a cruising altitude between 25,000 and $45,000 \mathrm{ft}$ osl (between 7,000 and 14,000 $\mathrm{m}$ osl).

Cabin pressurization during flight maintains the barometric pressure inside the airplane clearly higher than outside, even though cruising altitude is high. International laws stipulate that cabin pressure must not surpass that measured at $8,000 \mathrm{ft}$ osl [7]. In a study conducted on 240 flights, barometric pressures measured in the aircraft cabins were similar to those obtained between 5,000 and $8,000 \mathrm{ft}$ osl with a mean value of approximately $6,214 \mathrm{ft}$ osl [8]. Higher levels of pressurization decrease the energy available for other aircraft systems, reduce the operational lifetime of aluminium airframes, and necessitate increased structural weight, resulting in decreased fuel efficiency. In cabins pressurized at $8,000 \mathrm{ft}$ osl, the barometric pressure decreases from $760 \mathrm{~mm} \mathrm{Hg}$ at sea level to $565 \mathrm{~mm} \mathrm{Hg}$, hence, the $\mathrm{PiO}_{2}$ also undergoes a decrease of $40 \mathrm{~mm} \mathrm{Hg}$ in comparison to the values measured at sea level (table 1). Consequently, there is a decrease in $\mathrm{PaO}_{2}$ and in the percentage of oxygen saturated haemoglobin $\left(\mathrm{SaO}_{2}\right)$.
Table 1. Decrease of oxygen tensions with altitude and barometric pressure

\begin{tabular}{|c|c|c|c|c|}
\hline \multicolumn{2}{|c|}{ Altitude } & \multirow{2}{*}{$\begin{array}{l}\mathrm{BP} \\
\mathrm{mm} \mathrm{Hg}\end{array}$} & \multirow{2}{*}{$\begin{array}{l}\mathrm{PiO}_{2} \\
\mathrm{~mm} \mathrm{Hg}\end{array}$} & \multirow{2}{*}{$\begin{array}{l}\mathrm{PaO}_{2} \\
\mathrm{~mm} \mathrm{Hg}\end{array}$} \\
\hline $\mathrm{ft}$ osl & $\mathrm{m}$ osl & & & \\
\hline 0 & 0 & 760 & 150 & 100 \\
\hline 1,000 & 305 & 733 & 144 & 95 \\
\hline 2,000 & 610 & 707 & 139 & 90 \\
\hline 3,000 & 915 & 681 & 133 & 85 \\
\hline 4,000 & 1,220 & 656 & 128 & 80 \\
\hline 5,000 & 1,526 & 632 & 123 & 75 \\
\hline 6,000 & 1,831 & 609 & 118 & 70 \\
\hline 7,000 & 2,136 & 587 & 113 & 66 \\
\hline 8,000 & 2,441 & 565 & 109 & 62 \\
\hline 9,000 & 2,746 & 543 & 104 & 58 \\
\hline 10,000 & 3,050 & 523 & 100 & 54 \\
\hline
\end{tabular}

$\mathrm{BP}=$ Barometric pressure; $\mathrm{PiO}_{2}=$ inspiratory oxygen partial pressure; $\mathrm{PaO}_{2}=$ arterial oxygen partial pressure.

$1 \mathrm{ft}=0.3048 \mathrm{~m}$.

In practice, breathing at 8,000 or at $5,000 \mathrm{ft}$ osl corresponds to breathing at sea level a hypoxic mixture with an oxygen percentage of 15.1 or $17.1 \%$, respectively. In healthy subjects exposed to hypoxic mixtures with percentages of oxygen between 15.1 and $17.1 \%$, the $\mathrm{PaO}_{2}$ may vary between 53 and $64 \mathrm{~mm} \mathrm{Hg}$, with a $\mathrm{SaO}_{2}$ between 85 and $91 \%$, in relationship to age, basal $\mathrm{PaO}_{2}$ values and minute ventilation [1]. Moreover, it has been shown that in healthy subjects moving from sea level to an altitude of $8,000 \mathrm{ft}$ osl leads to an average fall in the $\mathrm{SaO}_{2}$ of $4.4 \%$ [9]. The authors also found that $7.4 \%$ of subjects met criteria for acute mountain sickness and that cumulative prevalence of altitude-related malaise, muscular discomfort and fatigue increased at $8,000 \mathrm{ft}$ exposure [9]. In this study, the effect of aircraft-cabin altitude on passenger discomfort and oxygen saturation was not evaluated in respiratory patients. Obviously, subjects with impaired gas exchange and a reduced baseline $\mathrm{PaO}_{2}$ value may be likely heading towards severe oxygen desaturation, when exposed to a hypoxic environment. As a general rule, chronic respiratory patients with $\mathrm{PaO}_{2}$ values $<67 \mathrm{~mm}$ $\mathrm{Hg}$ at sea level can have a $\mathrm{PaO}_{2}<50 \mathrm{~mm} \mathrm{Hg}$ during an ordinary air flight [10].

The decrease in $\mathrm{PiO}_{2}$ and the consequent decrease in $\mathrm{PaO}_{2}$ lead to the stimulation of chemoreceptors and to the increase in minute ventilation as a reflex. Changes in minute ventilation in relation to oxygen tension in healthy subjects are shown in figure 1, modified from Zhang and Robbins [11]. In healthy subjects, the increase in minute 
ventilation due to high-altitude hypoxia is mainly due to an increase in the tidal volume rather than the respiratory rate, even though individual variability should be considered [12]. Healthy subjects are characterized by a wide ventilatory reserve; therefore, the increased minute ventilation is generally well tolerated. On the other hand, respiratory patients may not tolerate exposure to even slightly hypoxic mixtures. In these patients, even a moderate increase in ventilation could exhaust the ventilatory reserve, which may already be reduced at rest. In turn, this can aggravate the reduced exercise tolerance and cause an increase in exertion dyspnoea. Additionally, in these patients, increased respiratory work leads to an increase in the blood flow to the respiratory muscles, which is subtracted from the cardiac output addressed to the limb muscles, thereby further limiting exercise capacity.

Besides the increase in minute ventilation, hypobaric hypoxia induces other cardiovascular compensatory answers such as an increase in heart rate and cardiac output and a vasoconstriction of the pulmonary circulation. There is a wide individual variability in both ventilatory response and hypoxic vasoconstriction of pulmonary vessels [13]. In healthy subjects, the hypoxic vasoconstriction redistributes pulmonary blood flow, causing an increased perfusion in the upper part of the lungs. This may reduce the mismatch in the perfusion/ventilation ratio, which may maintain the $\mathrm{PaO}_{2}$ at an acceptable level during ordinary air travel [12]. Respiratory patients may have significant alterations of the perfusion/ventilation ratio, with poorly ventilated areas and the presence of pulmonary hypertension. The hypoxia-induced pulmonary vasoconstriction may further worsen the increase of the dead space and the pulmonary hypertension, which may further deteriorate the $\mathrm{PaO}_{2}$.

It is of note that there is a difference between what levels of hypoxia man can tolerate acutely and what can be tolerated after acclimatization. The incidence and severity of high-altitude illness increase with the altitude and ascent rate, because each factor influences the magnitude of hypobaric hypoxic stress. The incidence rate of acute mountain sickness in the general tourist population at about $8,202 \mathrm{ft}(2,500 \mathrm{~m})$ is reported at $20-25 \%$, increasing to $40-50 \%$ in trekkers and climbers near $13,123 \mathrm{ft}$ $(4,000 \mathrm{~m})$ [14]. When an ascent to about $4,000 \mathrm{~m}$ occurs over a number of hours rather than days, the incidence of acute mountain sickness increases to over 90\% [14].

The time from takeoff to cruise altitude averages 20 min, thus the hypobaric hypoxic stress is acute for passengers whilst flying. In chronic respiratory patients, acute hypoxic challenge seems to be well tolerated both in laboratory and flight settings, even when the $\mathrm{PaO}_{2}$ falls to $50 \mathrm{~mm} \mathrm{Hg}$. Patients with chronic airway obstruction exposed to acute hypoxic challenge reported mild symptoms such as shortness of breath, dizziness or light-headedness, which did not correlate with the level of hypoxemia [15]. Other studies in COPD patients reported dyspnoea as a unique symptom $[16,17]$ or no symptoms $[10$, $18,19]$. It is of note that all these studies were conducted in COPD patients with mild to moderate severity of disease. Accordingly, no conclusions can be drawn about patients with more severe disease. Progressive exposure to mild hypoxic challenge does not appear to be affected by preexisting chronic respiratory disease. In mild to moderate COPD patients, Graham and Houston [20] reported that resting $\mathrm{PaO}_{2}$ dropped to $51.5 \mathrm{~mm} \mathrm{Hg}$ within $3 \mathrm{~h}$ of ascent to $6,300 \mathrm{ft}(1,920 \mathrm{~m})$. In this study, patients complained of mild symptoms of fatigue and insomnia after ascent [20]. By contrast, long-term residence at altitude was associated with increased mortality and a higher incidence of cor pulmonale in COPD patients [21, 22].

\section{Respiratory Diseases and Air Travel}

\section{Asthma}

Asthma is the most frequent respiratory disease reported by air travellers [2]. There are no contraindications to air travel for patients with stable and well-controlled asthma. It is important that patients do not interrupt their usual treatment on the occasion of the trip and that they carry along a short-acting $\beta_{2}$-agonist, i.e. salbutamol, and a cycle of oral steroids in case of an emergency during the trip [2]. Patients with unstable asthma or those who have had a recent exacerbation of the disease should be dissuaded from air travel, until the illness is completely stabilized and controlled [2].

\section{COPD}

Patients affected by COPD are particularly susceptible to develop respiratory failure during flights $[18,19,23-$ 25]. In the study by Christensen et al. [18], at $8,000 \mathrm{ft} 53$ and $33 \%$ of COPD patients experienced $\mathrm{PaO}_{2}$ levels below 55 and $50 \mathrm{~mm} \mathrm{Hg}$, respectively. In COPD patients, the ability to increase minute ventilation in response to the hypoxia is limited and the presence of an alteration in the perfusion/ventilation ratio makes it often difficult for them to maintain adequate oxygenation during the flight. Moreover, in these patients even modest physical activity during the flight at high altitude can worsen their gas exchange $[16,18,19]$. In COPD patients, the risk of develop- 
ing respiratory insufficiency during air travel is generally proportionate to the severity of the disease. High-risk patients are those who report dyspnoea on exertion or tend to present hypercapnia or with $\mathrm{PaO}_{2}$ values $<70 \mathrm{~mm}$ $\mathrm{Hg}$ or $\mathrm{SaO}_{2}$ values $<92 \%$ at sea level and patients with maximal voluntary ventilation $<40 \mathrm{l} / \mathrm{min}$ [26]. On the whole, patients with clinically unstable COPD should be dissuaded from undertaking air travel. The recommendations of the British Thoracic Society [1] and the guidelines of the Aerospace Medical Association [2] also suggest that all COPD patients should undergo a clinical and functional evaluation of fitness for flight before departure.

Chronic hypoxia in COPD is known to be associated with cognitive impairment [27]. Less well understood is the effect of acute hypoxia on cognitive function in COPD patients. Interestingly, a recent study [28] suggested that hypoxic COPD patients receiving supplemental oxygen, when placed on room air, did not have a deterioration in cognitive function. In this study, the cognitive function was assessed by 20 -min simulated driving performance and psychomotor reaction times. It is to ascertain whether or not COPD patients exposed to acute hypoxia during air travel may have any deterioration in cognitive function.

COPD patients are at a high risk for venous thromboembolism, because of a variety of factors including limited mobility, inflammation, and comorbidities, and venous thromboembolism events can play a role in acute exacerbation of COPD [29]. Additionally, there is a relationship between airplane travel and venous thromboembolism. A recent meta-analysis showed that air travel is associated with a threefold higher risk for venous thromboembolism, with a dose-response relationship of $18 \%$ higher risk for each 2-hour increase in travel duration [30]. It is still unknown whether air travel can increase the risk of venous thromboembolism events in COPD patients.

\section{Pneumothorax}

Spontaneous pneumothorax or pneumomediastinum must be excluded before air travel. Boyle's law states that the volume of a gas is inversely proportionate to its pressure in a closed space. Thus, in an airplane cabin, as the barometric pressure decreases when the airplane reaches cruising altitude, so the air volume in closed body cavities increases. It has been calculated that the air volume of a closed cavity, such as a pneumothorax, can increase approximately $30 \%$ when moving from sea level to $8,000 \mathrm{ft}$ osl [1]. Therefore, the presence of a pneumothorax is an absolute contraindication to air travel $[1,2]$, since the pressure in the pneumothorax may critically increase during the trip [31].

Airline companies suggest waiting 6 weeks after recovering from a pneumothorax, before flying. This rule is based on the probability of a relapse, which is high during the 6 weeks immediately following a first episode of pneumothorax. However, this rule is arbitrary since the kind of pneumothorax, the presence of an underlying pulmonary disease and the kind of treatment are not considered. In fact, if a pneumothorax is treated with thoracotomy and surgical or talc pleurodesis, the probability of a relapse is extremely low and 6 weeks after recovery there are no more restrictions on air travel [1]. On the contrary, in case of other therapeutic options or in subjects with a concomitant respiratory disease or in smokers, the risk of relapse is considerable for at least 1 year after the first episode. Hence, these patients are urged to consider alternative forms of transportation for at least 1 year [1].

Few data are available regarding the prevalence of pneumothorax associated with air travelling in patients with cystic or bullous lung diseases. Recently, in a retrospective study of 449 patients affected by interstitial lung diseases with high prevalence of spontaneous pneumothorax, Taveira-Da Silva et al. [32] showed that there was a relatively low risk of pneumothorax following air travel. No patient with pulmonary fibrosis or sarcoidosis presented with pneumothorax after air travel. In patients with lymphangioleiomyomatosis, the authors reported a $2.9 \%$ frequency of a new pneumothorax in those who travelled by airplane and a $1.3 \%$ frequency in those who travelled by ground. However, since a new pneumothorax was more likely in patients with large cysts and more severe disease, the authors concluded that in patients with lymphangioleiomyomatosis the prevalence of pneumothorax associated with air travel may be related to the high incidence of pneumothorax and not to travel itself.

Although patients with extensive bullous emphysema may head for a bullae expansion as a consequence of decrease of ambient pressure, the available literature suggests that the real risk of pneumothorax is negligible [33]. Yanda and Herschensohn [34] took 4 COPD patients with air trapping to a simulated altitude of $18,000 \mathrm{ft}(5,488 \mathrm{~m})$ and did not find evidence of worsening pulmonary function or pneumothorax. Moreover, Tomashefski et al. [35] brought 6 COPD patients with blebs and bullae to a simulated altitude of $18,000 \mathrm{ft}$ at a rate of $1,000 \mathrm{ft} / \mathrm{min}$ and found no radiographic evidence of bullae distention or pneumothoraces. The reason for 
the absence of pneumothoraces in patients with bullous disease has not been elucidated. Bullae may likely communicate with the airways to a greater extent than expected, allowing for pressure equalization.

\section{Bronchogenic Cyst}

Bronchogenic cysts are the result of an abnormal bronchial development from the primitive ventral foregut, and are located either within the lung or in the mediastinum. They are often asymptomatic, however emergencies may be caused by a sudden increase in the size and rupture of the cyst following a rapid decompression. Rupture of the cyst wall may result in entrainment of air into adjacent pulmonary vessels whose walls have also been damaged during the rupture of the cyst. As a consequence, air embolism into the systemic circulation and cerebral ischemia may occur.

A few cases of cerebral air embolism have been reported in airplane passengers after bronchogenic cyst rupture [36-39]. In these case reports, patients collapsed during decompression and suffered brain injury; most of the cases were fatal $[36,37,39]$. Subjects with bronchogenic cyst should be advised against activities leading to rapid changes in ambient pressure, such as flying, diving or high-altitude climbing or consider elective surgical treatment.

\section{Restrictive Pulmonary Diseases}

A case of acute cor pulmonale, after intercontinental air travel, has been described in a patient with congenital kyphoscoliosis [40]. The episode of pulmonary hypertension and right heart insufficiency was attributed to the prolonged exposure to a hypoxic environment. Subsequently, three studies have demonstrated that patients with a restrictive defect due exclusively to interstitial lung diseases $[19,41,42]$ or to other causes such as kyphoscoliosis [41], can develop a significant hypoxemia when exposed to hypoxic mixtures, simulating an air flight. In these patients, $\mathrm{PaO}_{2}$ values under hypoxic stimulus were positively correlated with $\mathrm{PaO}_{2}$ values at rest and with values for lung diffusion capacity for carbon monoxide (DLCO) and were negatively correlated with the partial pressure of carbon dioxide in the arterial blood $\left(\mathrm{PaCO}_{2}\right)$ [41]. Moreover, the decreases in $\mathrm{PaO}_{2}$ and $\mathrm{SaO}_{2}$ worsened when patients performed modest physical activity during the test [19].

Both in patients with a restrictive defect and in patients with COPD, the ability to increase the minute ventilation in response to hypoxia is limited, and the presence of an altered perfusion/ventilation ratio can deter- mine a reduction of $\mathrm{PaO}_{2}$ and $\mathrm{SaO}_{2}$ values during air travel, down to particularly critical levels. Therefore, it is advisable that these patients undergo a clinical and functional evaluation of fitness for flight in anticipation of air travel or that they consider alternative forms of transport in case of instability or exacerbation of the disease [26].

\section{Cystic Fibrosis}

Patients affected by cystic fibrosis with lung damage are susceptible to the negative effects of hypobaric hypoxia at high altitude $[43,44]$ and the induced oxygen desaturation is predicted by resting spirometry data [44]. Moreover, in these patients the environment of the aircraft cabin can represent a further risk factor, due to a significant decrease in cabin air humidity. Comfortable humidity conditions are considered to be $40-70 \%$ relative humidity at sea level. The guidelines for humidity in aircraft cabin are between 12 and 22\% relative humidity [45]. Cabin air humidity depends upon aircraft type, cruising altitude, ventilation rate and the number of people on board [45]. In-flight measurements have shown relative cabin humidity dropping from at least 47 to $11 \%$ within 30 min of ascent [46]. Humidity and temperature of inspired air can remarkably alter the function of airway mucosa [47]. Accordingly, in subjects with cystic fibrosis or bronchiectasis the low humidity rate could increase the risk of bronchospasm and mucus production, leading to mucus plugs and probably atelectasis. For these patients a clinical and functional evaluation of fitness for flight is advisable as well, when programming air travel.

\section{Obstructive Sleep Apnoea Syndrome}

Periodic breathing and central apnoeas may occur in normal subjects during sleep at high altitude [48]. Therefore, in patients affected by obstructive sleep apnoea syndrome the respiratory pattern may deteriorate significantly while sleeping during a flight, as may occur on long-distance flights. However, systematic studies of the effects of air travel on these patients are lacking. The case of an obese patient with respiratory sleep disorders who developed heart and respiratory insufficiency after two air flights and staying at high altitude, has been described [49]. Therefore, patients with obstructive sleep apnoea syndrome treated with mechanic ventilation in CPAP mode should be cautious and avoid long-distance air trips. In case they undertake air travel, they should inform the airline company of their problem and provide themselves with a ventilator and avoid alcohol before and during the flight [1]. According to the general prescription [50], patients affected by obstructive sleep apnoea 
Table 2. Prediction equations of $\mathrm{PaO}_{2}$ at high altitude

\begin{tabular}{lll}
\hline Equation & Authors & Used for \\
\hline $\mathrm{PaO}_{2} A L T, \mathrm{~mm} \mathrm{Hg}=22.8-(2.74 \cdot \mathrm{Alt}, \mathrm{ft})+0.68 \cdot \mathrm{PaO}_{2} \mathrm{SL}, \mathrm{mm} \mathrm{Hg}$ & Gong et al. [15] & COPD patients \\
$\mathrm{PaO}_{2} \mathrm{CAB}, \mathrm{mm} \mathrm{Hg}=0.519 \cdot \mathrm{PaO}_{2} \mathrm{SL}, \mathrm{mm} \mathrm{Hg}+11.855 \cdot \mathrm{FEV}, 1-1.76$ & Dillard et al. [23] & COPD patients \\
$\mathrm{PaO}_{2} \mathrm{CAB}, \mathrm{kPa}=0.74+\left(0.39 \cdot \mathrm{PaO}_{2} \mathrm{SL}, \mathrm{kPa}+(0.033 \cdot \mathrm{DLco}, \%\right.$ pred $)$ & Christensen et al. [41] & Patients with restrictive defect
\end{tabular}

$\mathrm{PaO}_{2} A L T=$ Predicted oxygen partial pressure at a certain altitude; Alt = expected altitude; $\mathrm{PaO}_{2} S L=$ oxygen partial pressure measured at sea level; $\mathrm{PaO}_{2} C A B=$ oxygen partial pressure expected at $8,000 \mathrm{ft}$ (cruise altitude); FEV $\mathrm{F}_{1}=$ forced expiratory volume at $1 \mathrm{~s}$; DLco = lung diffusion capacity for carbon monoxide. Conversion factors: $1 \mathrm{kPa}=7.5 \mathrm{~mm} \mathrm{Hg} ; 1 \mathrm{ft}=0.3048 \mathrm{~m}$.

syndrome should also avoid sedatives before and during the flight.

\section{Pulmonary Hypertension}

Patients with both primitive and secondary pulmonary hypertension are at high risk of complications during air travel. Considering the important individual variability to pulmonary vasoconstriction induced by hypoxia, even a light worsening of hypoxemia during flight can induce a significant increase in pressure in the pulmonary artery leading to a serious right cardiac failure [12, 26]. Although there are no studies which specifically deal with this problem, it is prudent to consider severe (NYHA class III and IV) pulmonary hypertension as a contraindication to air travel [26].

\section{Assessment of Fitness for Flight}

\section{Walking Test}

The so-called 50 -metre walking test $[1,2,51,52]$ is a very simple test and it is widely used in the medical departments of the airline companies. It consists in walking $50 \mathrm{~m}$. The incapability to cover the distance or the onset of severe dyspnoea indicates that a clinical and functional assessment should be performed and that the patient may require oxygen supplementation during the flight. As with other tests based on walking capacity, the 50-metre walking test is considered a measure of the cardiopulmonary reserve to exercise. In particular, it is thought that assessing the ability to increase minute ventilation and cardiac output when walking is a simple, practical and reliable way to calculate the cardiopulmonary reserve that respiratory patients utilize when they face the physiological requests determined by the hypobaric hypoxia during flight [1].
The 50-metre walking test has not yet been standardized. Moreover, the potential travellers do not even perform the test, instead they are simply asked if they are able to walk $50 \mathrm{~m}$ [25]. Unlike the 50-metre walking test, the 6-min walking test (6MWT) has been standardized and validated $[53,54]$. The $6 \mathrm{MWT}$ is widely used in lung function laboratories and the British Thoracic Society [1] recommends its use to evaluate the fitness to fly. We have recently demonstrated that in chronic respiratory patients, affected by COPD or interstitial lung disease, the desaturation observed during the hypoxia altitude simulation test (HAST) is strictly correlated and predicted by the 6MWT-induced desaturation [42].

\section{Hypoxemia Prediction Equations}

Equations have been published which predict the $\mathrm{PaO}_{2}$ values at altitudes other than sea level. Gong et al. [15] provided the first equation in 1984, which refers to COPD patients (table 2). Subsequently, Dillard et al. [23] and Christensen et al. [41] proposed prediction equations for patients with COPD or restrictive pulmonary diseases (table 2).

The equations have been obtained by submitting the subjects to hypobaric rooms or to HASTs and provide $\mathrm{PaO}_{2}$ and $\mathrm{SaO}_{2}$ values with $90 \%$ confidence intervals equal to $\pm 7.5 \mathrm{~mm} \mathrm{Hg}$ and to $\pm 2-4 \%$, respectively [1]. The equations are therefore sufficiently reliable to identify subjects who are not at risk of critical hypoxemia at high altitude $\left(\mathrm{SaO}_{2}\right.$ at sea level $\left.>95 \%\right)$ and those who are probably at risk $\left(\mathrm{SaO}_{2}\right.$ at sea level $\left.<92 \%\right)$. The subjects with $\mathrm{SaO}_{2}$ values between 92 and $95 \%$ need to perform the HAST, given the margin of error of these equations [1].

\section{Hypoxia Altitude Simulation Test}

The ideal test which exposes the subject to hypoxia in a hypobaric room requires complex and expensive equip- 


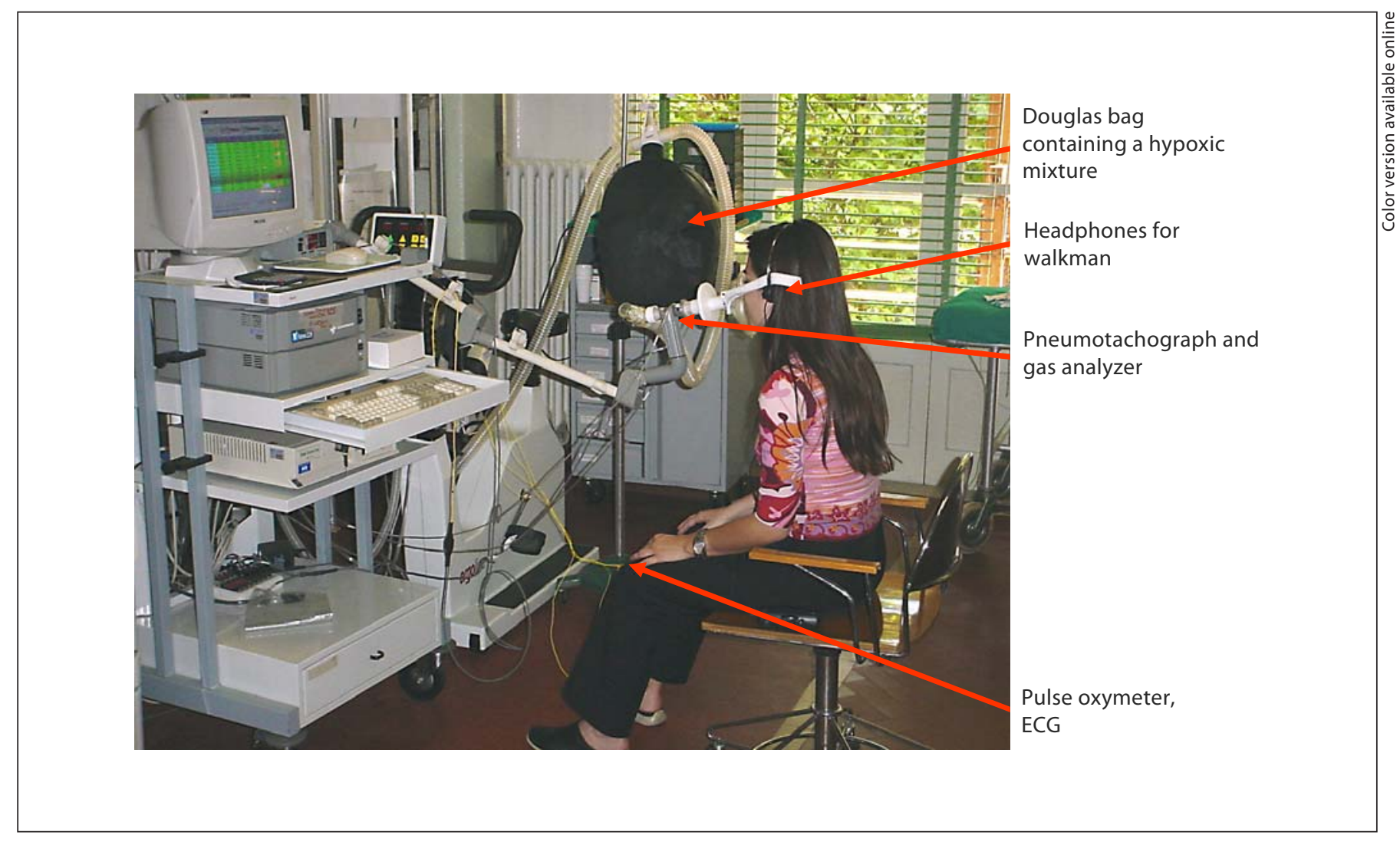

Fig. 2. Equipment necessary to perform the HAST.

ment which is not always available. The most frequently used test is the so-called HAST, proposed by Gong et al. [15]. This test consists in exposing the subject to a hypoxic mixture. In practice, the subject breathes a mixture of $15 \%$ oxygen and $85 \%$ nitrogen, from a Douglas bag, through a mouthpiece or a facial mask, connected to a two-way valve. Usually, during the test a pulse oximeter registers oxygen saturation $\left(\mathrm{SpO}_{2}\right)$ or, less commonly, the $\mathrm{PaO}_{2}$ is measured; an ECG is also continuously monitored in order to find possible rhythm alterations. The equipment required to perform the test is illustrated in figure 2 . The exposure to the hypoxic mixture lasts 20 min or until the pulse oximeter data reaches a stable condition. A subject is considered to be at risk of air travelinduced hypoxemia, a condition which would require oxygen supplementation, if a value of $\mathrm{SpO}_{2}<85 \%$ or of $\mathrm{PaO}_{2}<50 \mathrm{~mm} \mathrm{Hg}$ is recorded during the test [1]. These cut-off values have been selected arbitrarily, even if they are considered to be quite reasonable by the experts [1]. In case a significant hypoxemia occurs, the test must be repeated with oxygen supplementation through nasal cannula to titrate the necessary flow during the flight, starting with a flow of $21 / \mathrm{min}[26,55]$. In case of borderline results it can be useful to perform a second test while the patient performs modest exercise, such as walking on a treadmill [55].

It has been demonstrated that the HAST induces a decrease of the $\mathrm{PaO}_{2}$ comparable to the one obtained after exposure in a hypobaric room, with an equivalent barometric pressure of $8,000 \mathrm{ft}$ osl, both in COPD patients [51, $52]$ and in healthy subjects $[56,57]$. This test is considered a reliable tool in predicting the hypoxemia measured during air travel both in healthy subjects [58] and in COPD patients [59]. Moreover, in patients affected by COPD, cystic fibrosis or interstitial lung disease the need of oxygen therapy during flight may be importantly overestimated if the hypoxemia-predicted equations are considered instead of the HAST [60]. Therefore, the HAST is considered the gold standard in the assessment of fitness for flight $[1,24,55,61,62]$, even if at the moment it is not commonly used in clinical practice [63]. 
Fig. 3. Algorithm for the assessment of fitness to fly in respiratory patients.

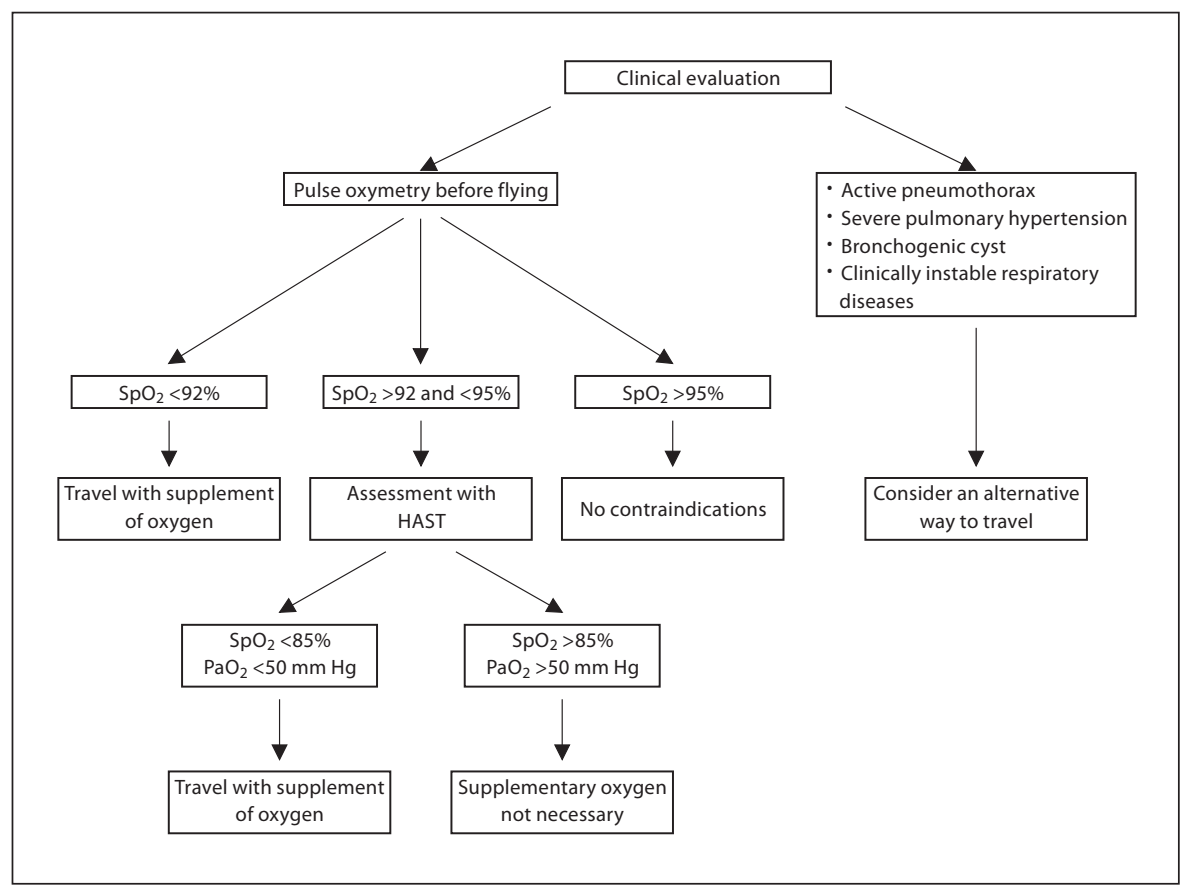

Cramer et al. [64] proposed an interesting alternative to the HAST, as described by Gong et al. [15], which uses the plethysmographic box as a hermetically sealed environment, where the addition of nitrogen leads to a hypoxic condition. The test requires that the examined subject remains exposed to a hypoxic environment for $10 \mathrm{~min}$.

\section{Conclusions}

In patients with respiratory disease there are no absolute contraindications to air travel, apart from pneumothorax, bronchogenic cyst and severe pulmonary hypertension. In respiratory patients, it is recommended to perform a clinical and functional assessment of fitness to fly in order to reduce the risk and identify patients which require oxygen supplementation during the flight. The algorithm described in figure 3 is based on the current international literature $[1,2,26,55]$ and summarizes the approach to the respiratory patient before air travel.

Generally, the patients cannot carry onboard the aircraft any personal device for oxygen therapy, however most airline companies provide oxygen supplementation during the flight, after medical prescription. Obviously, this service has to be arranged in advance with the airline companies, which usually ask for at least a 48 -hour notice before the departure, and it is generally free. However, the airline companies do not provide oxygen supplementation during the stay in the airports. Recently, in the USA the Federal Aviation Administration (FAA) has established that the airline companies can embark passengers who require personal portable oxygen concentrators approved by the FAA [26], in order to encourage travelling in respiratory patients.
References
British Thoracic Society Standards of Care Committee: Managing passengers with respiratory disease planning air travel: British Thoracic Society recommendations. Thorax 2002;57:289-304.

- 2 Aerospace Medical Association, Air Transport Medicine Committee: Medical guidelines for air travel, ed 2. Aviat Space Environ Med 2003;74:A1-A19.
-3 Gendreau MA, DeJohn C: Responding to medical events during commercial airline flights. N Engl J Med 2002;346:1067-1073.

-4 Morgan MD: Air travel and respiratory disease. BMJ 2002;325:1186-1187.

5 DeHart RL: Health issue of air travel. Annu Rev Public Health 2003;24:133-151. 
6 Gerencher K: Airlines get guidance on inflight medical assistance from ground. April 27, 2007. Available at: www.marketwatch. com (accessed February 10, 2008).

7 Code of Federal Regulations: Title 14, Part 25.841. Washington, Government Printing Office, 1986.

8 Cottrell JJ: Altitude exposures during aircraft flight. Chest 1988;93:81-84.

-9 Muhm JM, Rock PB, McMullin DL, Jones SP, Lu IL, Eilers KD, Space DR, McMullen A: Effect of aircraft-cabin altitude on passenger discomfort. N Engl J Med 2007;357:18-27.

10 Schwartz JS, Bencowitz HZ, Moser KM: Air travel hypoxemia with chronic obstructive pulmonary disease. Ann Intern Med 1984; 100:473-477.

- 11 Zhang S, Robbins PA: Methodological and physiological variability within the ventilatory response to hypoxia in humans. J Appl Physiol 2000;88:1924-1932.

-12 Mortazavi A, Eisenberg MJ, Langleben D, Ernst P, Schiff RL: Altitude-related hypoxia: risk assessment and management for passengers on commercial aircraft. Aviat Space Environ Med 2003;74:922-927.

13 Luks AM, Swenson ER: Travel to high altitude with pre-existing lung disease. Eur Respir J 2007;29:770-792.

14 Gallagher SA, Hackett PH: High-altitude illness. Emerg Med Clin North Am 2004;22; 329-355.

15 Gong H, Tashkin DP, Lee EY, Simkons MS: Hypoxia-altitude simulation test. Evaluation of patients with chronic airway obstruction. Am Rev Respir Dis 1984;130:980-986.

- 16 Akero A, Christensen CC, Edvardsen A, Skjonsberg OH: Hypoxaemia in chronic obstructive pulmonary disease patients during a commercial flight. Eur Respir J 2005;25: 725-730.

17 Dillard TA, Beninati WA, Berg BW: Air travel in patients with chronic obstructive pulmonary disease. Arch Intern Med 1991;151: 1793-1795.

- 18 Christensen CC, Ryg M, Refvem OK, Skjonsberg OH: Development of severe hypoxaemia in chronic obstructive pulmonary disease patients at $2,438 \mathrm{~m}(8,000 \mathrm{ft})$ altitude. Eur Respir J 2000;15:635-639.

19 Seccombe LM, Kelly PT, Wong CK, Rogers PG, Lim S, Peters MJ: Effect of simulated commercial flight on oxygenation in patients with interstitial lung disease and chronic obstructive pulmonary disease. Thorax 2004:59:966-970.

20 Graham WG, Houston CS: Short-term adaptation to moderate altitude. Patients with chronic obstructive pulmonary disease. JAMA 1978;240:1491-1494.

-21 Moore LG, Rohr, AL, Maisenbach JK, Reeves JT: Emphysema mortality is increased in Colorado residents at high altitude. Am Rev Respir Dis 1982;126:225-228.
22 Cote TR, Stroup DF, Dwyer DM, Horan JM, Peterson DE: Chronic obstructive pulmonary disease mortality. A role for altitude. Chest 1993;103:1194-1197.

23 Dillard TA, Berg BW, Rajagopal KR, Dooley JW, Mehm WJ: Hypoxemia during air travel in patients with chronic obstructive pulmonary disease. Ann Intern Med 1989;111:362367.

24 Shesser R: Medical aspects of commercial air travel. Am J Emerg Med 1989;7:216-226.

25 Johnson AO: Chronic obstructive pulmonary disease $\cdot 11$ : fitness to fly with COPD. Thorax 2003;58:729-732.

26 Mohr LC: Hypoxia during air travel in adults with pulmonary disease. Am J Med Sci 2008; 335:71-79.

27 Incalzi RA, Gemma A, Marra C, Muzzolon R, Capparella O, Carbonin P: Chronic obstructive pulmonary disease. An original model of cognitive decline. Am Rev Respir Dis 1993; 148:418-424.

28 Pretto JJ, McDonald CF: Acute oxygen therapy does not improve cognitive and driving performance in hypoxaemic COPD. Respirology 2008;13:1039-1044.

29 Rizkallah H, Man SF, Sin DD: Prevalence of pulmonary embolism in acute exacerbations of COPD: a systematic review and metaanalysis. Chest 2009;135:786-793.

30 Chandra D, Parisini E, Mozaffarian D: Metaanalysis: travel and risk for thromboembolism. Ann Intern Med 2009;151:180-190.

31 Fuchs HS: Idiopathic spontaneous pneumothorax and flying. With particular reference to the etiological role of decreased atmospheric pressure, pressure breathing, increased gravitational forces, and anti-G-suit action. Aerosp Med 1967;38:1283-1285.

32 Taveira-Da Silva AM, Burstein D, Hathaway OM, Fontana JR, Gochuico BR, Avila NA, Moss J: Pneumothorax after air travel in lymphangioleiomyomatosis, idiopathic pulmonary fibrosis, and sarcoidosis. Chest 2009;136:665-670.

33 Parker GW, Stonehill RB: Further considerations of the roentgenologic evaluation of flying personnel at simulated altitude. Aeromed Acta 1961;32:501-504.

34 Yanda RL, Herschensohn HL: Changes in lung volumes of emphysema patients upon short exposures to simulated altitude of 18,000 feet. Aerosp Med 1964;35:12011203.

35 Tomashefski JF, Feeley DR, Shillito FH: Effects of altitude on emphysematous blebs and bullae. Aerosp Med 1966;37:1158-1162 .

36 Zaugg M, Kaplan V, Widmer U, Baumann PC, Russi EW: Fatal air embolism in an airplane passenger with a giant intrapulmonary bronchogenic cyst. Am J Respir Crit Care Med 1998;157:1686-1689.

- 37 Almeida FA, Desouza BX, Meyer T, Gregory S, Greenspon L: Intrapulmonary bronchogenic cyst and cerebral gas embolism in an aircraft flight passenger. Chest $2006 ; 130$ 575-577.
38 Belcher E, Lawson MH, Nicholson AG, Davison $\mathrm{A}$, Goldstraw P: Congenital cystic adenomatoid malformation presenting as inflight systemic air embolisation. Eur Respir J 2007;30:801-804.

-39 Edwardson M, Wurth D, Lacy JM, Fink J, Becker K: Cerebral air embolism resulting in fatal stroke in an airplane passenger with a pulmonary bronchogenic cyst. Neurocrit Care 2009; 10:218-221.

-40 Noble JS, Davidson JA: Cor pulmonale presenting in a patient with congenital kyphoscoliosis following intercontinental air travel. Anaesthesia 1999;54:361-363.

41 Christensen CC, Ryg MS, Refvem OK, Skjonsberg OH: Effect of hypobaric hypoxia on blood gases in patients with restrictive lung disease. Eur Respir J 2002;20:300-305.

42 Chetta A, Castagnetti C, Aiello M, Sergio F, Fabiano N, Tzani P, Marangio E, Olivieri D: Walking capacity and fitness to fly in patients with chronic respiratory disease. Aviat Space Environ Med 2007;78:789-792.

43 Oades PJ, Buchdahl RM, Bush A: Prediction of hypoxaemia at high altitude in children with cystic fibrosis. BMJ 1994;308:15-18.

44 Buchdahl RM, Babiker A, Bush A, Cramer D: Predicting hypoxaemia during flights in children with cystic fibrosis. Thorax 2001; $56: 877-879$

45 Hinninghofen H, Enck P: Passenger well-being in airplanes. Auton Neurosci 2006;129: $80-85$.

46 Eng W, Harada L, Jagerman L: The wearing of hydrophilic contact lenses aboard a commercial jet aircraft. Aviat Space Environ Med 1982;53:235-238

47 Williams R, Rankin N, Smith T, Galler D, Seakins P: Relationship between the humidity and temperature of inspired gas and the function of the airway mucosa. Crit Care Med 1996;24:1920-1929.

48 Weil JV: Sleep at high altitudes; in Kryger MH, Roth T, Dement WC (eds): Principles and Practice of Sleep Medicine, ed 2. London, Saunders, 1989, pp 224-230.

49 Toff NJ: Hazards of air travel for the obese: Miss Pickwick and the Boeing 747. J R Coll Physicians Lond 1993;27:375-376.

50 Prisant LM, Dillard TA, Blanchard AR: Obstructive sleep apnea syndrome. J Clin Hypertens 2006;8:746-750.

51 Mills FJ, Harding RM: Fitness to travel by air. I. Physiological considerations. BMJ 1983;286:1269-1271.

52 Lyznicki JM, Williams MA, Deitchman SD, Howe JP 3rd: Council on Scientific Affairs, American Medical Association. Medical oxygen and air travel. Aviat Space Environ Med 2000;71:827-831.

-53 American Thoracic Society Statement: Guidelines for the six-minute walk test. Am J Respir Crit Care Med 2002;166:111-117. 
54 Chetta A, Pisi G, Aiello M, Tzani P, Olivieri $\mathrm{D}$ : The walking capacity assessment in the respiratory patient. Respiration 2009;77: 361-367.

55 Dine CJ, Kreider ME: Hypoxia altitude simulation test. Chest 2008;133:1002-1005.

56 Dillard TA, Moores LK, Bilello KL, Phillips YY: The pre-flight evaluation. A comparison of the hypoxia inhalation test with hypobaric exposure. Chest 1995;107:352-357.

-57 Naughton MT, Rochford PD, Pretto JJ, Pierce RJ, Cain NF, Irving LB: Is normobaric simulation of hypobaric hypoxia accurate in chronic airflow limitation? Am J Respir Crit Care Med 1995;152:1956-1960.
58 Kelly PT, Swanney MP, Frampton C, Seccombe LM, Peters MJ, Beckert LE: Normobaric hypoxia inhalation test versus response to airline flight in healthy passengers. Aviat Space Environ Med 2006;77:1143-1147.

59 Kelly PT, Swanney MP, Seccombe LM, Frampton C, Peters MJ, Beckert L: Air travel hypoxemia versus the hypoxia inhalation test in passengers with COPD. Chest 2008; 133:920-926.

60 Martin SE, Bradley JM, Buick JB, Bradbury I, Elborn JS: Flight assessment in patients with respiratory disease: hypoxic challenge testing vs. predictive equations. QJM 2007; 100:361-367.
61 Dillard TA, Bansal AK: Commentary: pulse oximetry during airline travel. Aviat Space Environ Med 2007;78:143-144.

62 Mohr LC: The hypoxia altitude simulation test: an increasingly performed test for the evaluation of patients prior to air travel. Chest 2008;133:839-842.

63 Coker RK, Partridge MR: Assessing the risk of hypoxia in flight: the need for more rational guidelines. Eur Respir J 2000;15:128130.

64 Cramer D, Ward S, Geddes D: Assessment of oxygen supplementation during air travel. Thorax 1996;51:202-203. 